\title{
INFLUENCE OF SECOND PHASE PARTICLES ON RECRYSTALLISATION OF COLD-ROLLED LOW CARBON MICROALLOYED STEELS DURING ISOTHERMAL ANNEALING
}

\author{
Carlos Capdevila a, Tommy De Cock ${ }^{\mathrm{b}}$, Carlos García-Mateo, Francisca García \\ Caballero $^{\mathrm{d}}$, and Carlos García de Andrés ${ }^{\mathrm{e}}$ \\ Department of Physical Metallurgy, Centro Nacional de Investigaciones Metalúrgicas \\ (CENIM-CSIC), Avda. Gregorio del Amo, 8, 28040 Madrid, Spain. \\ a ccm@cenim.csic.es, ${ }^{b} \underline{\text { tdecock@cenim.csic.es }},{ }^{c} \underline{\text { cgm@@cenim.csic.es }}{ }^{\mathrm{d}} \underline{\text { fgc@@cenim.csic.es }}$ \\ e cgda@cenim.csic.es
}

KEYWORDS: Low carbon steel; recrystallisation; cementite; thermoelectric power.

\begin{abstract}
The recrystallisation behaviour of two cold-rolled low carbon microalloyed steels with different Ti content was investigated by thermoelectric power (TEP) measurements and metallography. It was shown that recrystallisation was more sluggish in the higher Ti grade steel as compare with traditional ELC and LC steels. The existence of Ti in solid solution together with the pinning effect of Nb-, Vand Ti-rich particles are likely to be responsible for such behaviour. Metallographic etching with picral revealed that cementite act as preferential nucleation site for recrystallization.
\end{abstract}

\section{Introduction}

In the low-carbon sheet steel industry it is very important to obtain sheets with excellent forming properties. One of the most critical problems in the production of deep-drawing material is the control of texture and anisotropy, which in the case of low-carbon steels is related to the so-called $\gamma$-fiber $(\mathrm{ND} / /<100>$ ). A lot of research has gone into the understanding of the influence of the interstitial elements $(\mathrm{C}, \mathrm{N})$ on the annealing textures during rapid annealing of cold-rolled low-carbon steels and it is generally accepted that these elements have a detrimental effect on the plastic anisotropy when they are uncombined [1].

Two important ways of limiting the solid solution content of interstitial elements are studied in this work: precipitation of cementite and addition of microalloying elements such as $\mathrm{Ti}, \mathrm{Nb}$ or $\mathrm{V}$. Both are effective method to fix the $C$ and $N$ content and are favorable to the development of $\{111\}$ texture during rapid annealing.

This paper deals with the role of cementite and second phase particles on the evolution of recrystallized volume fraction with temperature during rapid annealing of cold rolled low carbon steels. Results presented in this work allow us to conclude that the smaller cementite particle size and 
the more homogeneous distribution, the faster recrystallization kinetics. Likewise, the addition of titanium as microalloying element retards recristallisation kinetics considerably.

\section{Experimental Procedure}

The composition of the studied steels is given in Table 1. Two microalloyed steels (C and D) will be compared with the extra low (A1 and A2) and low carbon steels (B) which do not contain any microalloying elements. The material was subjected to an austenitic rolling with a final rolling temperature (FRT) as indicated in Table 1. Then, it was air-cooled until coiling, which occurred at a coiling temperature CT. Finally, a cold rolling stage took place with a rolling reduction (CR). The applied heat treatment for the study of the recrystallization consists of heating at $20^{\circ} \mathrm{C} / \mathrm{s}$ up to temperatures ranging from 600 to $700^{\circ} \mathrm{C}$, an isothermal holding stage at these temperatures and finally quenching to room temperature.

Table 1. Chemical composition and main processing parameters of the studied steels (all contents are

\begin{tabular}{cccccc}
\multicolumn{7}{c}{ in wt.\%). } \\
\hline Steel & A1 & A2 & B & C & D \\
\hline $\mathrm{C}$ & 0.014 & 0.014 & 0.080 & 0.0740 & 0.0740 \\
$\mathrm{Si}$ & 0.007 & 0.006 & 0.011 & 0.022 & 0.018 \\
$\mathrm{Mn}$ & 0.19 & 0.21 & 0.17 & 1.060 & 1.080 \\
$\mathrm{P}$ & 0.007 & 0.007 & 0.004 & 0.009 & 0.008 \\
$\mathrm{~S}$ & 0.016 & 0.014 & 0.005 & 0.0023 & 0.0032 \\
$\mathrm{Al}$ & 0.055 & 0.053 & 0.053 & 0.040 & 0.042 \\
$\mathrm{~N}$ & 0.0025 & 0.0028 & 0.0040 & 0.0036 & 0.0037 \\
$\mathrm{Cr}$ & --- & --- & --- & 0.0170 & 0.0200 \\
$\mathrm{Ni}$ & --- & --- & --- & 0.0240 & 0.0200 \\
$\mathrm{Cu}$ & --- & --- & --- & 0.0160 & 0.0130 \\
$\mathrm{Mo}$ & --- & --- & --- & 0.0020 & 0.0040 \\
$\mathrm{Nb}$ & --- & --- & --- & 0.0450 & 0.0460 \\
$\mathrm{~V}$ & --- & --- & --- & 0.0540 & 0.0510 \\
$\mathrm{Ti}$ & 0.001 & 0.001 & 0.001 & 0.0120 & 0.0020 \\
$\left.\mathrm{FRT} \mathrm{[}{ }^{\circ} \mathrm{C}\right]$ & 890 & 890 & 865 & 901 & 895 \\
$\mathrm{CT}\left[{ }^{\circ} \mathrm{C}\right]$ & 740 & 550 & 728 & 622 & 574 \\
$\mathrm{CR}[\%]$ & 70 & 75 & 75 & 65 & 61 \\
\hline
\end{tabular}

For the metallographic study samples were then mounted in bakelite, ground and polished with diamond paste to a $1 \mu \mathrm{m}$ surface finish. For the measurement of the recrystallised volume fraction the samples were etched with a 2-\% nital solution and the micrographs subsequently analysed using a point count method.

In order to study the evolution of the recrystallisation with thermoelectric power measurements (TEP), samples $30 \mathrm{~mm}$ in length, $2 \mathrm{~mm}$ in width and $0.8 \mathrm{~mm}$ in thickness were used. A schematic representation of the TEP apparatus is given elsewhere [2]. The experimental procedure of the TEP measurement is the following: the sample is pressed between two blocks of a reference metal (in this case, pure iron). One of the blocks is at $15{ }^{\circ} \mathrm{C}$, while the other is at $25{ }^{\circ} \mathrm{C}$ to obtain a temperature difference $\Delta T$. A potential difference $\Delta V$ is generated at the reference metal contacts. The apparatus does not give the absolute the TEP value of the sample $\left(S^{*}\right)$, but a relative TEP $(\Delta S)$ in comparison to the TEP of pure iron $\left(S_{0}{ }^{*}\right)$ at $20^{\circ} \mathrm{C}$. $\Delta S$ is given by the following relation: 


$$
\Delta S=S *-S_{0} *=\frac{\Delta V}{\Delta T}
$$

The TEP value does not depend on the shape of the sample, which is a great advantage of this technique. Moreover, the measurement is performed very quickly (less than $1 \mathrm{~min}$ ) and precisely (about $\pm 0.5 \%$ ). The resolution is of the order of $1 \mathrm{nV} / \mathrm{K}$.

\section{Results and Discussion}

\subsection{Recrystallised fraction}

Figure 1 shows the evolution of the recrystallized volume fraction for the studied steels as a function of time at 600,640 and $700{ }^{\circ} \mathrm{C}$. It is clear that recrystallization kinetics is faster in ELC and LC steels than in $\mathrm{C}$ and $\mathrm{D}$ microalloyed steels. There is a considerable delay on recrystallization kinetics on steels $\mathrm{C}$ and $\mathrm{D}$. The reason for this behaviour is the main aim of this paper. Likewise, from Fig. 1(c) it can be concluded that the addition of $\mathrm{Ti}$ (C steel) to a $\mathrm{Nb}+\mathrm{V}$ containing steel (D steel) retards the recrystallisation process even more, whereas the steels $\mathrm{A} 1$, A2 and B recrystallise almost immediately at $700{ }^{\circ} \mathrm{C}$ annealing temperature.
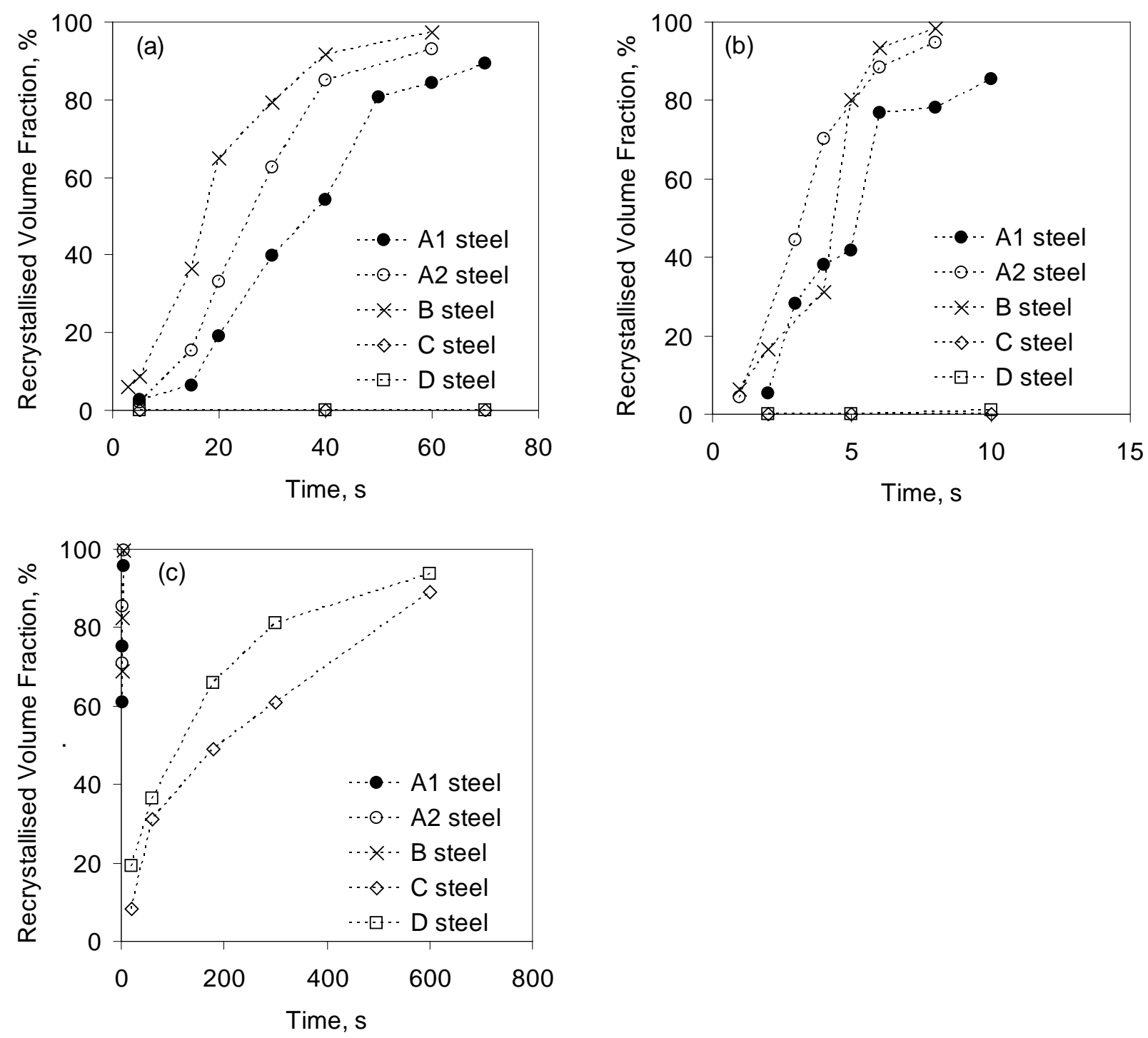

Fig 1.- Evolution of recrystallized volume fraction at (a) $600{ }^{\circ} \mathrm{C}$, (b) $640{ }^{\circ} \mathrm{C}$, and (c) $700{ }^{\circ} \mathrm{C}$. 


\subsection{Influence of the cementite particles}

A picral etching procedure has been used to study the presence and distribution of cementite in as-received microstructures. Even though this reagent tends to overestimate the total amount of cementite in the material it can be clearly seen in Fig. 2 that several differences in cementite morphology is detected in the as-received microstructure of studied steels.
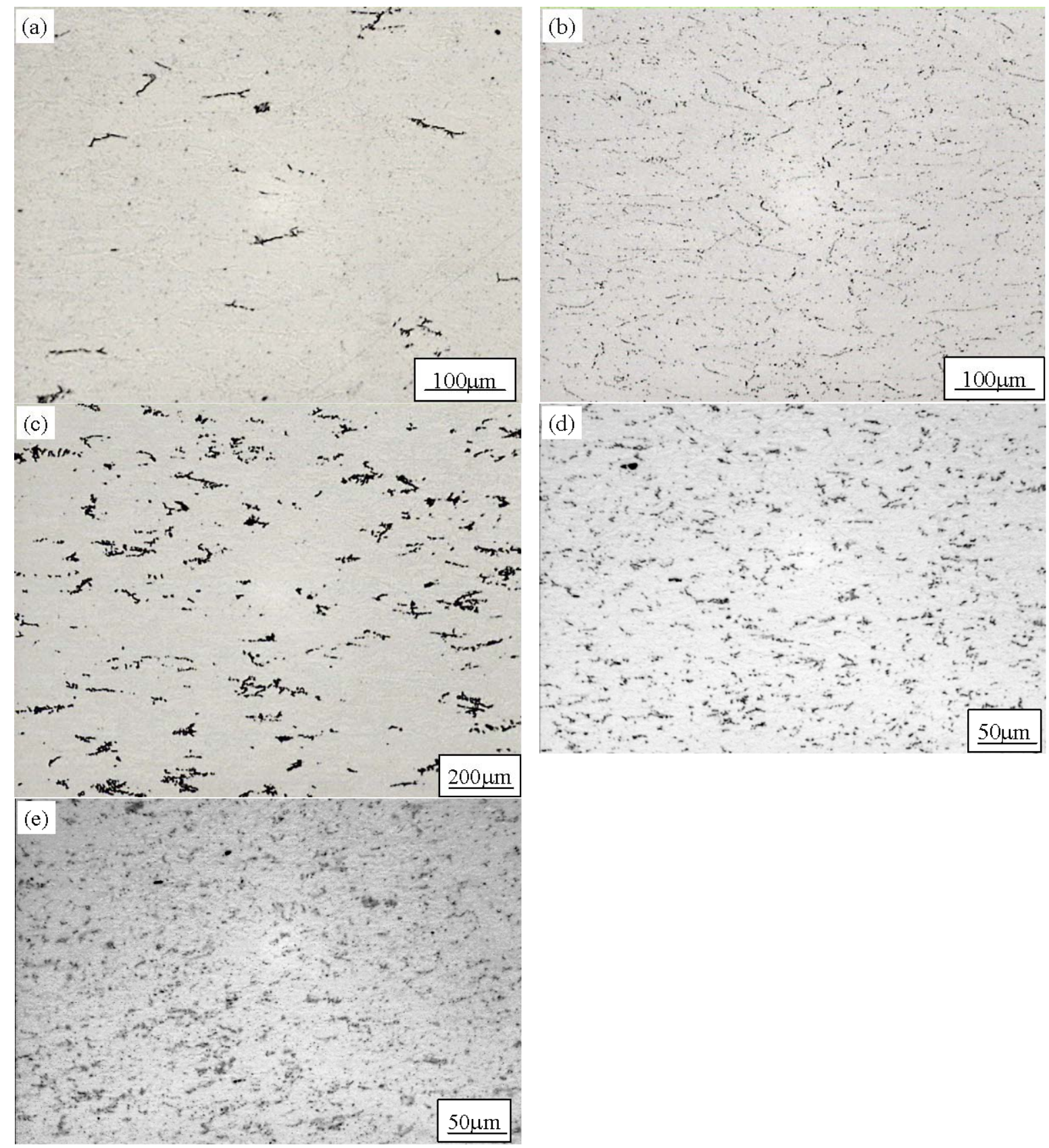

Fig. 2.- As-received microstructure revealed with picral of the studied steels (a) A1, (b) A2, (c) B, (d) C, and

(d) D.

The influence of coiling temperature on cementite morphology in ELC steels is very strong. In this sense, the lower coiling temperature, the finer and more homogeneous distributed cementite particles are (Figs. 2(a) and 2(b)). On the other hand, the amount of cementite increases as carbon content increases, as expected (more cementite in B, C and D steels as compare with A1 and A2 steels). Thus, blocks of cementite in the LC steel studied are detected (Fig 2(c)) meanwhile microalloyed steels 
show a very fine cementite particles (Figs. 2(d) and 2(e)), which is consistent with the low coiling temperature of these steels as compare with steel B.

Therefore, it could be concluded that decreasing coiling temperature during hot rolling a microstructure consisting of ferrite and finely distributed cementite particles along the grain boundaries and even within the grains is obtained, as it is clearly observed at Fig. 2(b), 2(d) and 2(e). These results are consistent with values listed in Table 2. In this table, the mean free distance of cementite particles $(\lambda)$ for the as-received microstructure of the studied steels is listed. The distance between particles is higher in a microstructre formed by coarse particles since they are scare. By contrast, the number of particles in a microstructure formed by fine particles is higher, and therefore, the distance between them is smaller. In this sense, the higher coiling temperature and lower carbon content, the higher $\lambda$ value is.

Table 2. Mean free distance of cementite particles in the as-received state

\begin{tabular}{ccc}
\hline Steel & $\mathrm{CT},{ }^{\circ} \mathrm{C}$ & $\lambda[\mu \mathrm{m}]$ \\
\hline A1 & 740 & 289,3 \\
A2 & 550 & 48,4 \\
B & 728 & 165,7 \\
C & 622 & 29,9 \\
D & 574 & 28,3 \\
\hline
\end{tabular}

The role of cementite on recrystallization is shown in Fig. 3. Using the Electron Channeling Contrast technique (ECC) [3] it has been observed that cementite particles are preferential nucleation sites of strain-free grains.

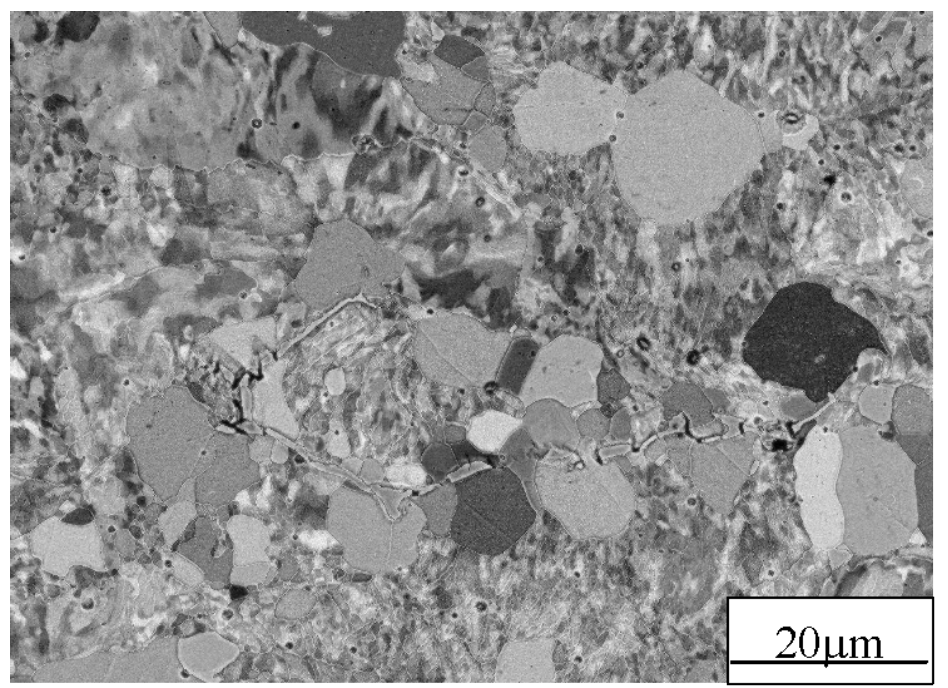

Fig.3. ECC micrograph sowing cementite as preferential nucleation site for recrystallisation.

Since lower coiling temperature promotes the presence of finer and higher volume fraction of cementite in the as-received microstructure, more nucleation sites for recrystallization are available during subsequent annealing. Thus, recrystallization kinetics proceeds faster as coiling temperature is decreased, which is consistent with results presented in Fig.1.

However, this conclusion can not explain the recrystallization behavior observed in C and D steels. Results presented in Fig. 2 and Table 2 indicate that cementite particles are present in an amount enough to boost recrystallization, but contrary to A2 steel, recrystallization is considerably delayed. 


\subsection{Thermoelectric power measurements}

MTDATA [4] calculations presented in Fig. 4 shows the evolution of second-phase particles present in $\mathrm{C}$ and $\mathrm{D}$ steels with temperature.

(a)
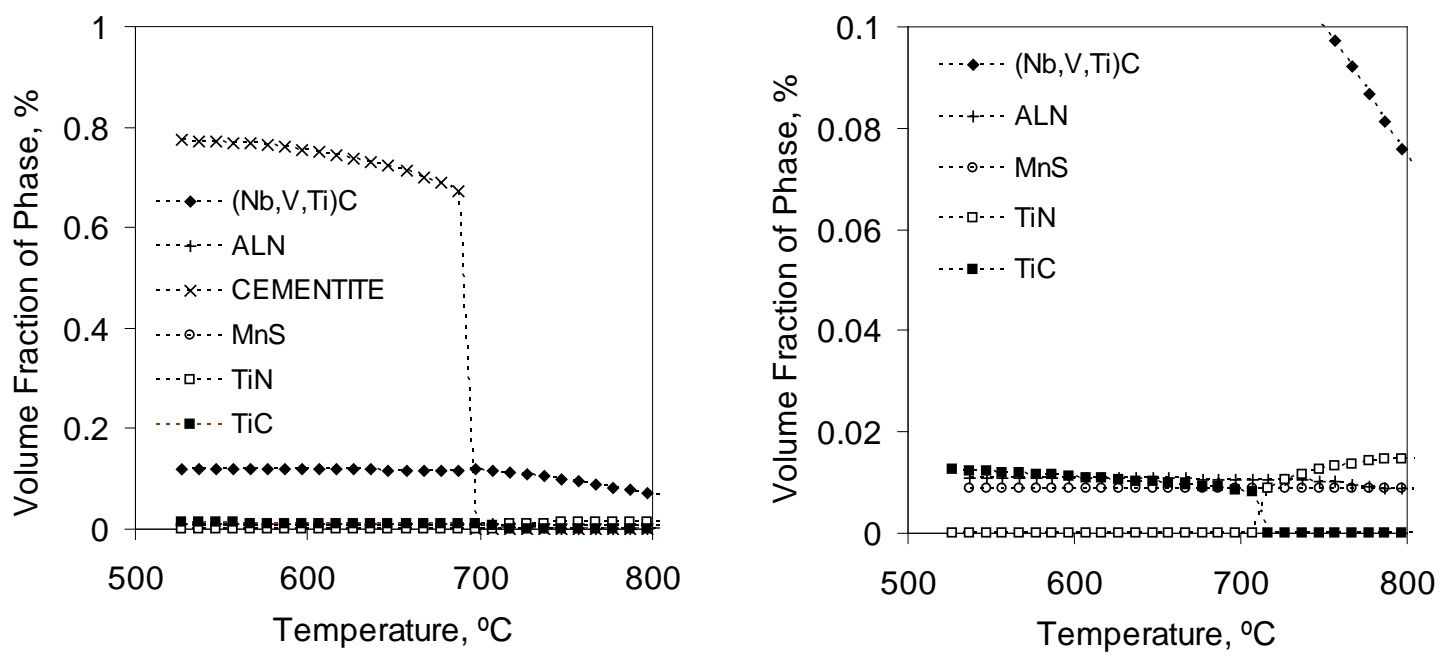

(b)
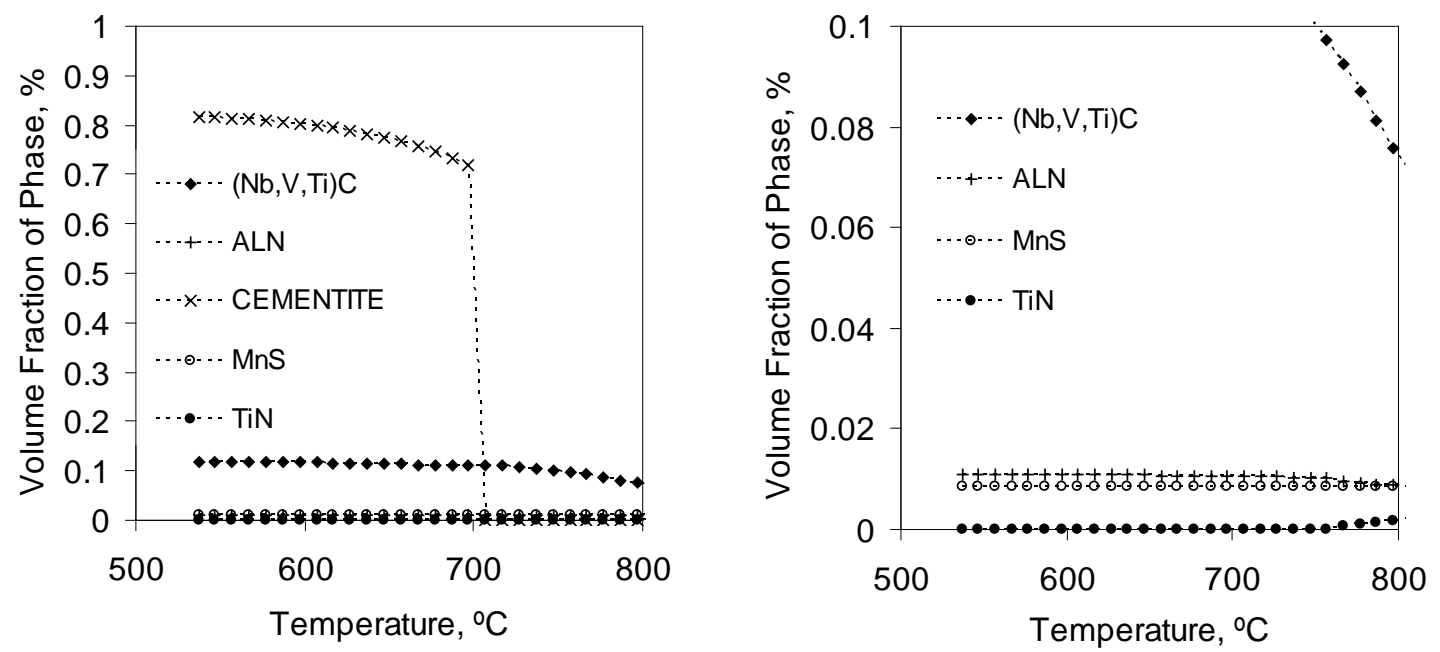

Fig. 4.- Second phase particles predicted by MTDATA in (a) steel C and (d) steel D.

According to calculations, in Ti-added microalloyed steel (C steel), the first compound which will be formed at high temperature, i.e. during solidification or in the delta ferrite region, is TiN. Additional TiC is be formed in the $\gamma$-region as temperature decrease. Niobium will combine to tie up the remaining carbon in the form of complex $\mathrm{Nb}$ and $\mathrm{V}$ carbides.

It is worth to notice the predicted presence of $\mathrm{TiC}$ in $\mathrm{C}$ steel, but not in $\mathrm{D}$ steel. A careful sight of Fig. 4(a) indicates that $\mathrm{TiC}$ is dissolved at $700{ }^{\circ} \mathrm{C}$, the temperature at which isothermal annealing is performed.

This result is consistent with TEP measurements shown in Fig. 5. In this figure, it is shown an increase of TEP values as recrystallization proceeds. However, TEP values for steel C are lower than those for steel $\mathrm{D}$ because of $\mathrm{TiC}$ dissolution during isothermal holding. The recovery and 
recrystallisation contribution is thought to be more significant to TEP than the negative contribution of dissolution [5].

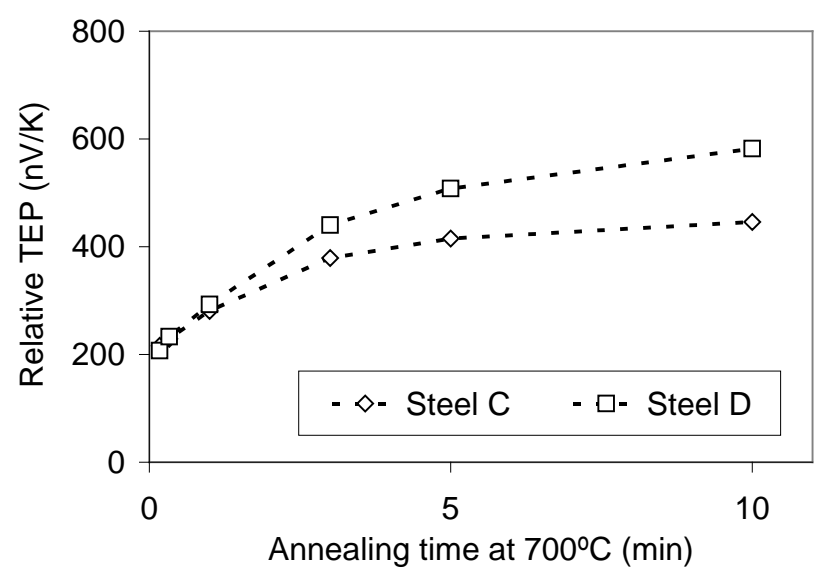

Fig. 5.- Relative TEP measurements performed during isothermal holding at $700{ }^{\circ} \mathrm{C}$ in steels $\mathrm{C}$ and $\mathrm{D}$.

It is well known the effect of $\mathrm{Ti}$ in solid solution delaying recrystallization [ref]. This can explain the delay on recrystallization of $\mathrm{C}$ steel as compare with steel $\mathrm{D}$.

On the other hand, the presence of particles predicted in Fig. 4 indicates that Zener pinning forces exerted by small second phase particles might be responsible for considerably retarded recrystallisation kinetics in the two microalloyed steels $C$ and $D$ in comparison with the extra low-carbon (ELC) steels A1 and A2 and the low-carbon (LC) steel B.

\section{CONCLUSIONS}

The recrystallisation of two microalloyed steels has been studied and compared with steels with two ELC and a LC steel. It has been seen that the recrystallisation is considerabily retarded in the microalloyed steels, and that the addition of $\mathrm{Ti}$ enhances this effect. The existence of $\mathrm{Ti}$ in solid solution together with the pinning effect of $\mathrm{Nb}, \mathrm{V}$ and $\mathrm{Ti}$ rich particles are likely to be responsible for such behaviour. The etching with picral revealed that finely distributed cementite act as preferential nucleation sites for recrystallization.

\section{References}

[1] R.K. Ray, J.J. Jonas and R.E. Hook: Inter. Mat. Rev. Vol. 39 No. 4 (1994), p. 129.

[2] A. Ney Jose Luiggi, Metall. Mater. Trans. A, 1998,29, 2669.

[3] Oatley CW. The scanning electron microscope, part 1, the instrument, 1st ed. (Cambridge University Press, UK 1972).

[4] Metallurgical and Thermochemical Databank, 1996, Teddington, Middlessex, National Physical Laboratory, UK, p.1.

[5] V. Sardoy, M. Bouzekri, P. Zimmer, J. Merlin: Proc. of the Intern. Symp. on modern LC and ULC sheet Steels for cold forming: Processing and Properties, Aachen (1998).

[6] T. Urabe and J.J. Jonas, ISIJ Int. Vol. 34 No. 5 (1994), p. 441 